\title{
An Idea of Compliment for "Tickling" Mind
}

\author{
Kosuke Ishii ${ }^{1)}$, and Natsuki Maruta ${ }^{1)}$ \\ 1) Kagoshima Immaculate Heart University and Kagoshima City Center for Gender Equality
}

\begin{abstract}
The purpose of this study is to try proposing the idea and analyzing about clinical usage of compliment, which heavily weighted in the Brief Therapy. Maruta and Ishii $(2008,2009)$ has been proposed "Tickling" as one of the ideas about compliment. The demonstrative study was defining "Tickling" as a compliment which was due to finding resource in the bitter reality based on the three effective conditions about intervention "small, acceptable, and funny" suggested by Hasegawa(2005). This study was conducted by using questionnaire, and searched the main factor of tickling and how it effects on feeling of comfortableness and process of cognition. From the result, some factors of tickling were clarified about their influence. Since the influence of titillating feeling with "tickling" could confirm, importance of "tickling" as contrive of compliment was shown that the tickling changes intrapersonal level of comfortableness and cognition regarding problem for positive way.
\end{abstract}

KEY WORDS: Tickling, Compliment, Change

\section{Purpose}

An Idea of Compliment for “Tickling” Mind

The purpose of this study is to try proposing the idea and analyzing about clinical usage of compliment, which heavily weighted in the brief-therapy, by demonstrating the compliment. Maruta and Ishii (2008, 2009) has been proposed "Tickling" as one of the ideas about compliment. The demonstrative study was conducted by using questionnaire, and defining "Tickling" as a compliment which was due to finding resource in the bitter reality based on the three effective conditions about intervention

CoRrespondence TO: ISHII, Department of Child studies, Kagoshima Immaculate Heart University, 2365 Amatatsu-cho, Satsumasendai-city, KAGOSHIMA, 895-0011, Japan.

e-mail: k.ishii@jundai.k-junshin.ac.jp "small, acceptable, and funny" suggested by Hasegawa(2005). The result shown that "Tickling" contains the senses of ticklish, accepted, and reality affirmative, and when the ticklish was sensed, the process of cognition toward problem tends to change as positively. The purpose of this study is to search the main factor of tickling, and how it effects on feeling of comfortableness and process of cognition.

\section{Method}

\section{Participants}

Participants were chosen from university students. There were total of 254 participants, and 232, including 52 males and 180 females, became an object after excluding data of missing value. This study was conducted in November to December in 2008.

\section{Questionnaire}

The questionnaire that consisted of 3 scales 
was made referring to the scale that Maruta and Ishii(2008) had produced based on preparatory investigations and previous study of (2004). The composition of the questionnaire is 1) demographic profile for each participant which included gender and age, 2) three brief settings of the students who have certain maladaptive problems (factor between individuals : having difficult to make friends, left behind study, juvenile delinquent who gets incomprehension ), 3) comfortable criterion that must be answered from student's standpoint about comfortableness of school, 4) tickling(compliment) scene from teacher to the particular student, 5) another comfortable criterion that must be answered from student's standpoint about after he or she get tickling, change acknowledgment regarding problem scale that is about how one's cognition about problem has been changed, tickling recognition scale that measures the feeling after ticklish word was given, and 6) free response.

\section{Results}

1. Ascertain the factorial structure for each scale and calculate subordinate scale score

The factor analysis for tickled recognition

The 3 factor structure was considered to be valid after 18 items were analyzed by principal factor method. The final pattern of factor and the correlation between factors after execute promax rotation are in Table1. Each factor was named; ticklish factor was the first $(\alpha=.91)$, remaining the status factor was the second $(\alpha=.91)$, and empathy acknowledgment factor was the third $(\alpha=.80)$.

Table 1

\begin{tabular}{|c|c|c|c|c|}
\hline & I & II & III & \\
\hline feel bashful & 1.01 & -.21 & -.01 & .74 \\
\hline feel ticklish & .96 & -.01 & -1.10 & .81 \\
\hline feel embarrassed & .83 & -.02 & .07 & .72 \\
\hline feel won the praise & .66 & .24 & -.04 & .69 \\
\hline feel proud of myself & .57 & .18 & -.05 & .48 \\
\hline feel encouragement & .41 & .32 & .12 & .56 \\
\hline feel to be able to accept myself & -.08 & 1.00 & -.05 & .82 \\
\hline understood & .04 & .79 & .03 & .71 \\
\hline able to think objectively & .09 & .75 & -.17 & .52 \\
\hline feel relieved & .18 & .72 & .00 & .73 \\
\hline feel ok to being myself & -.15 & .66 & .04 & .34 \\
\hline feel being affirmed from others & .17 & .48 & .21 & .60 \\
\hline feel getting understand from others & .27 & .42 & .28 & .73 \\
\hline feel not getting understand from others & .02 & .04 & -.80 & .59 \\
\hline feel denied from others & -.08 & .14 & -.79 & .56 \\
\hline feel not at home & .15 & -.10 & -.76 & .57 \\
\hline correlation factor & I & II & III & \\
\hline I & - & .74 & .49 & \\
\hline II & & - & .65 & \\
\hline III & & & 一 & \\
\hline
\end{tabular}


The factor analysis for comfortableness scale

The 3 factor structure was considered to be valid after 17 items were analyzed by principal factor method. The final pattern of factor and the correlation between factors after execute promax rotation are in Table2. Each factor was named; positive feeling factor was the first $(\alpha=.89)$, growth factor was the second $(\alpha=.90)$, and relax factor was the third $(\alpha=.84)$.

The factor analysis for variation about cognition regard problem

The 3 factor structure was considered to be valid after 30 items were analyzed by principal factor method. The final pattern of factor and the correlation between factors after execute promax rotation are in Table 3. Each factor was named; feeling of solved problem factor was the first $(\alpha=.89)$, and problem deterioration factor was the second $(\alpha=.79)$. Since the third factor was configured from only 2 factors, it was excluded from the data.

Table 2

Factor analysis of comfortableness scale

\begin{tabular}{|c|c|c|c|c|c|}
\hline & & I & II & III & \\
\hline like to stay at classroom & & .99 & -.08 & -.08 & .80 \\
\hline have good time at classroom & & .96 & -.14 & .01 & .77 \\
\hline fun to stay at classroom & & .74 & .13 & .08 & .78 \\
\hline make friends & & .64 & .28 & -.16 & .57 \\
\hline get cheerful feeling & & .55 & .29 & -.01 & .58 \\
\hline uninteresting to stay classroom & & -.37 & -.16 & -.04 & .26 \\
\hline muster motivation & & .07 & .85 & -.08 & .73 \\
\hline have someone to talk to & & .02 & .85 & -.07 & .67 \\
\hline able to set goal & & -.04 & .82 & .06 & .69 \\
\hline feel looked after from someone & & -.02 & .81 & .06 & .69 \\
\hline mentally growing & & .07 & .50 & .29 & .58 \\
\hline being able to feel relax & & .10 & -.17 & .91 & .78 \\
\hline being able to stay myself & & -.06 & .13 & .79 & .69 \\
\hline being able to stay calm & & .08 & .01 & .79 & .72 \\
\hline not being able to obedient myself & & .19 & -.03 & -.50 & .18 \\
\hline \multirow[t]{5}{*}{ feel comfortable } & & .23 & .08 & .45 & .46 \\
\hline & correlation factor & I & II & III & \\
\hline & I & - & .68 & .63 & \\
\hline & II & & - & .57 & \\
\hline & III & & & - & \\
\hline
\end{tabular}


Table 3

Factor analysis of acknowledgment variation on problem

\begin{tabular}{|c|c|c|c|c|}
\hline & I & II & III & \\
\hline motivated to solve problem & .89 & .03 & -.25 & .75 \\
\hline considering to change own behavior & .88 & .02 & -.25 & .74 \\
\hline ways to approaching problems has been changed & .86 & -.09 & -.16 & .74 \\
\hline found the things which should be done & .82 & .12 & -.05 & .63 \\
\hline if I get the same problem in future, my behavior will change & .81 & .08 & -.12 & .62 \\
\hline there should be something that I can do to solve the problem & .80 & .04 & -.04 & .62 \\
\hline got confident myself about solving the problem & .80 & -.15 & .05 & .74 \\
\hline I can understand the problem clearly & .78 & .25 & .06 & .59 \\
\hline the way of thinking has been changed & .77 & .01 & -.03 & .58 \\
\hline I admit that my behavior has a point for improvement & .76 & .26 & -.22 & .59 \\
\hline felt relieved & .75 & -.15 & .12 & .69 \\
\hline $\begin{array}{l}\text { the connection between the problem and myself have been } \\
\text { changed }\end{array}$ & .74 & -.01 & .13 & .60 \\
\hline countermeasure toward problem has been settled & .73 & .13 & .04 & .52 \\
\hline got new opinion & .71 & -.09 & -.08 & .52 \\
\hline I believe that I can do a lot of things & .70 & .08 & .04 & .49 \\
\hline feel fine & .70 & -.10 & .18 & .63 \\
\hline understood the importance of problem & 68 & .13 & .21 & .52 \\
\hline feel secure & .67 & -.22 & .10 & .62 \\
\hline reduced anxiety level & .66 & -.20 & .19 & .65 \\
\hline being able to organized own feeling & .66 & -.23 & .14 & .63 \\
\hline reduced stress level & .63 & .00 & .23 & .51 \\
\hline $\begin{array}{l}\text { found the exceptional behavior in myself that leads good } \\
\text { result }\end{array}$ & .63 & .03 & .16 & .45 \\
\hline increased stress level & -.10 & .90 & .09 & .80 \\
\hline feel depressed & -.02 & .82 & .20 & .59 \\
\hline feel confused & .10 & .66 & .14 & .37 \\
\hline realized seriousness of problem & .27 & .54 & -.18 & .39 \\
\hline problem became unconcern & -.11 & .18 & .77 & .50 \\
\hline feel fine even if I have problem & .23 & .10 & .63 & .46 \\
\hline correlation factor & I & II & III & \\
\hline I & - & -.22 & .21 & \\
\hline II & & - & -.40 & \\
\hline III & & & - & \\
\hline
\end{tabular}

In addition, subordinate scaling score was calculated from average score of recognition of tickling scale, comfortableness scale, and acknowledgement variation on problem scale, based on obtained raw score of subordinate scaling data from factor analysis. The average score and standard deviation of each subordinate scaling is shown in Table 4.

\section{Discussions about correlation and causation}

Cross correlation about tickling recognition scale, comfortableness scale, and 
acknowledgement variation on problem scale is shown on Table 4. Also, in order to discuss the influence about comfortableness scale and acknowledgment variation on problem scale from three subordinate scaling score in tickling recognition scale, multiple regression analysis was conducted based on each subordinate scaling score of comfortableness scale and acknowledgment variation on problem scale as a dependent variable. The result is shown on Table 5. The path diagram based on multiple regression analysis is shown Figure 1. In the Figure 1, correlation of subordinate scaling score about tickling recognition scale was also stated. Although correlation between independent variables was exceedingly high,
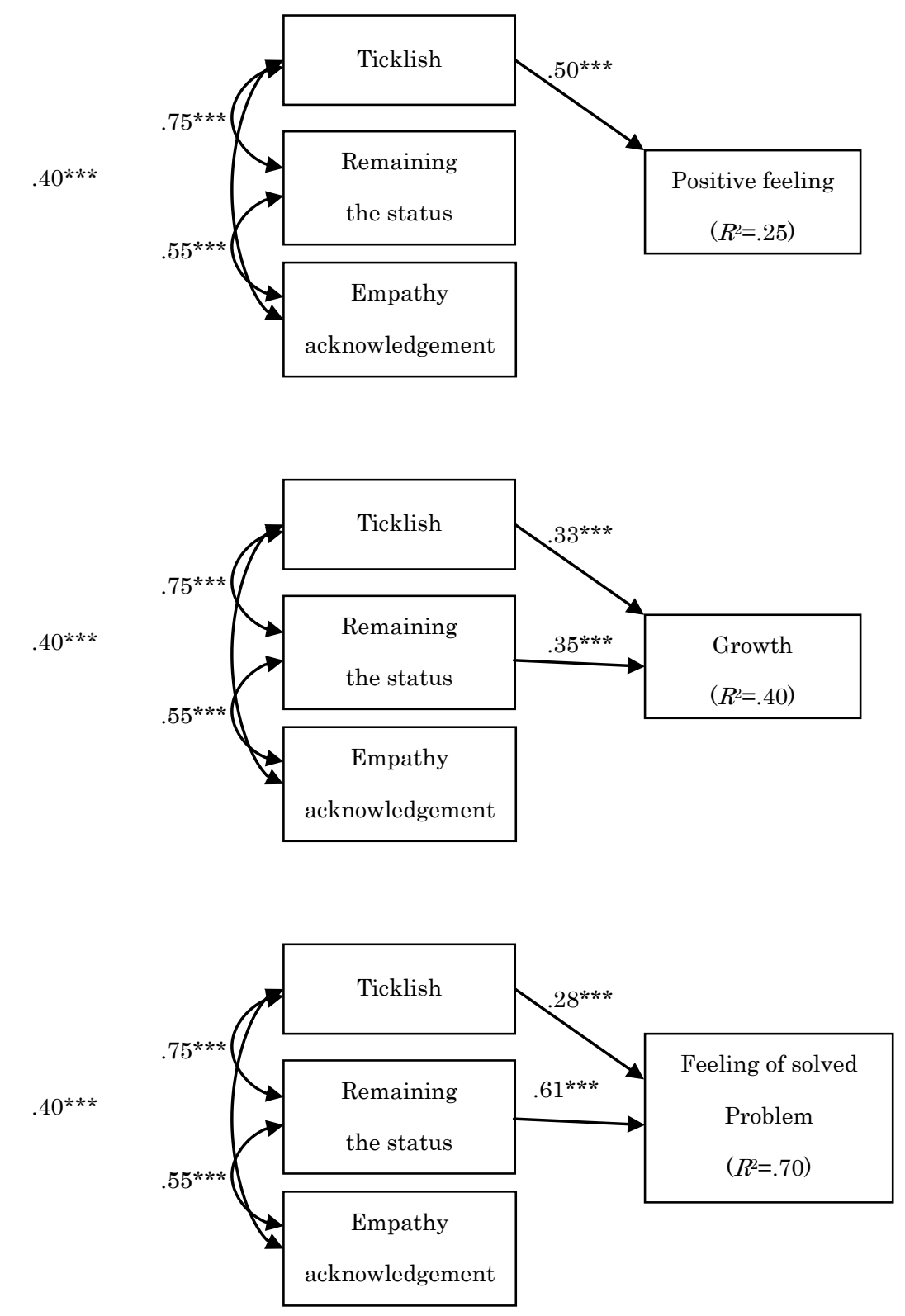

Figure 1. Path Diagram 

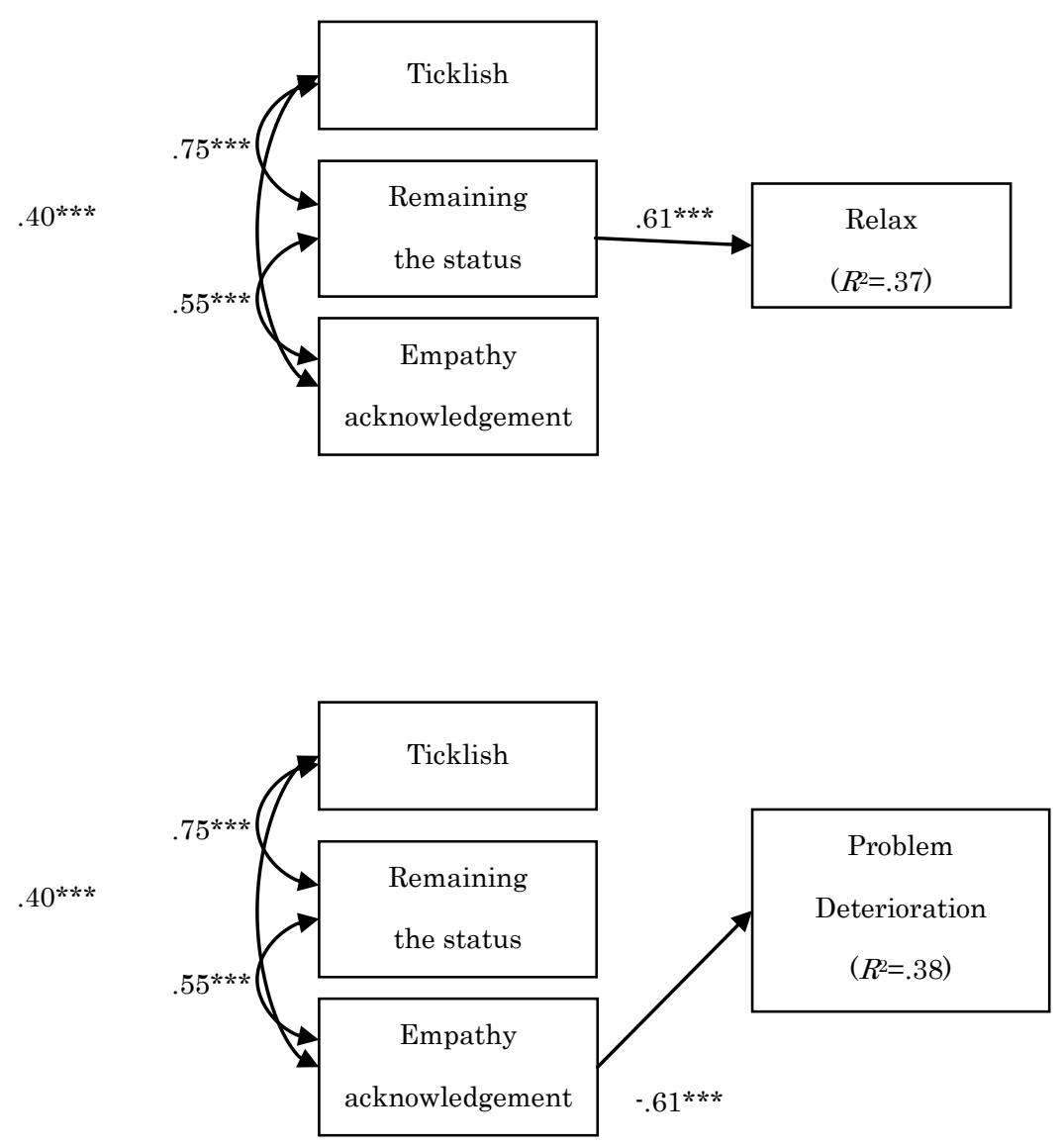

Figure1 (Continued). Path Diagram 
the variable of VIF and CI was not indicated multicollinearity. The result of multiple regression analysis, standard partial regression towards positive feeling about ticklish indicated significant, but there was no significance between the remaining the status and empathy cognition. Also, ticklish and remaining the status toward growth indicated significant, but level of significance could not found from empathy cognition toward growth. The remaining the status toward relax showed significance, but no significance was shown ticklish toward empathy cognition. Ticklish and remaining the status toward sense of resolution indicated significance, but ticklish toward empathy cognition did not shown significance. Empathy cognition toward deterioration of problem showed significance, but no significance was founded in remaining the status toward ticklish.

Table 4

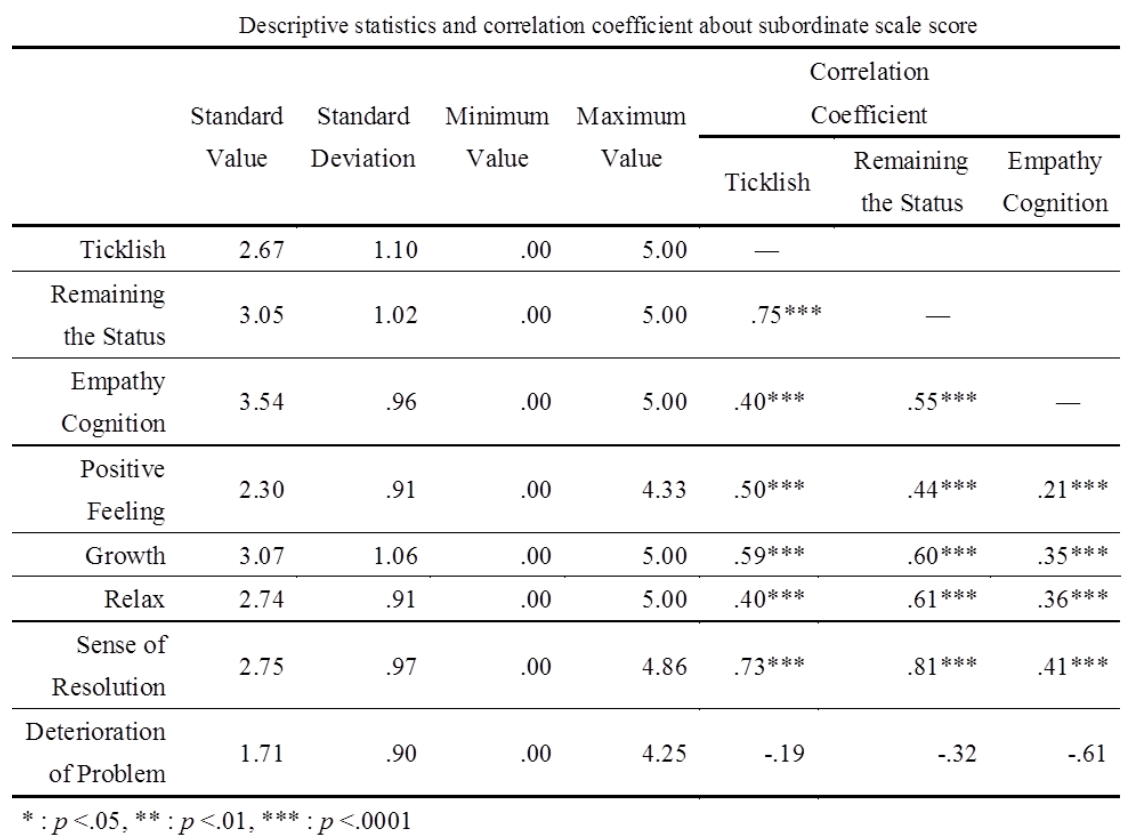

Table 5

\begin{tabular}{|c|c|c|c|c|c|}
\hline & \multicolumn{5}{|c|}{$\frac{\text { Result of multiple regression analysi }}{\beta}$} \\
\hline & $\begin{array}{l}\text { Positive } \\
\text { Feeling }\end{array}$ & Growth & Relax & $\begin{array}{l}\text { Sense of } \\
\text { resolution }\end{array}$ & $\begin{array}{c}\text { Deterioration } \\
\text { of Problem }\end{array}$ \\
\hline Ticklish & $.50^{* * * *}$ & $.33^{* * * *}$ & -.12 & $.28 * * *$ & .07 \\
\hline $\begin{array}{l}\text { Remaining } \\
\text { the Status }\end{array}$ & .14 & $.35^{* * * *}$ & $.61^{* * * *}$ & $.60 * * *$ & .03 \\
\hline $\begin{array}{l}\text { Empathy } \\
\text { Cognition }\end{array}$ & .01 & .34 & .03 & -.06 & -.61 \\
\hline$R^{2}$ & $.25 * * *$ & $.40 * * *$ & $.37 * * *$ & $.70 * * *$ & $.38^{* * * *}$ \\
\hline
\end{tabular}




\section{Discussions}

From the result of this research, some factors of tickling were clarified about their influence. First, titillating feeling with "tickling" made change the negative feeling about maladjusted environment, increased motivation about growth facilitated the transition of problem solving. Second, the feeling about maintain the same status increased relaxation and motivation about growth in maladjusted environment, and facilitated the change of problem solving. Finally, the recognition secured empathy suppressed impression about deterioration of problem. Since the influence of titillating feeling with "tickling" could confirm, importance of "tickling" as contrive of compliment was shown that the tickling changes intrapersonal level of comfortableness and cognition regarding problem for positive way.

\section{References}

Keizo, H., (2005). Solution Bank. Tokyo: KANEKOSHOBO.

Yukako, H., Takako, H., Kosuke, I., Junya, K., Kohei, S., Keizo, H. (2004). A Study of Communication between Clients and Counselors: Counselors' Responses and Clients' Cognitive Changes. (Counselor to Client no Communication ni kansuru Ichikosatu: Counselor no Oto to Client no Ninchitekihenka no Kanren). The 21th Conference presentation abstracts of the Japanese Association of Family Psychology.

Natsuki, M., Kosuke, I., (2008). A New Approach to the Compliment to Tickle Clients' Hearts I . (Kokoro wo Kusuguru Compliment ni yoru Igokochi Ninchi no Henka ni kansuru Kenkyu: Kainyu tosite no Kusuguri no Kanosei wo Saguru). The 25th Conference presentation abstracts of the Japanese Association of Family Psychology.

Natsuki, M., Kosuke, I., (2009). A New Approach to the Compliment to Tickle Clients' Hearts II . (Kokoro wo Kusuguru Compliment ni kansuru Kenkyu: Igokochi to Mondai no Toraekata no Henka ni Shoten wo Atete). The 26th Conference presentation abstracts of the Japanese Association of Family Psychology. 